\title{
Deteksi Myocardial Infarction Menggunakan Fitur Statistik Segmen-ST Elektrokardiogram dan Analisis Diskriminan
}

\section{(Detection of Myocardial Infarction Using ST-Segment Statistics Features Electrocardiogram and Discriminant Analysis)}

\author{
Dewi Cahya Fitri ${ }^{1}$, Nuryani Nuryani ${ }^{2}$, Anto Satriyo Nugraha ${ }^{3}$
}

\begin{abstract}
This paper describes the detection of myocardial infarction using the statistical mean features, including the mean, median, and standard deviation. The discriminant analysis method was used in the classification and was implemented using MATLAB software. The ECG signal obtained from the device was then processed. After that, the feature extraction was carried out. The results of the extraction were normalized so that al patient data had the same standard in amplitude wave magnitude. After normalization, the data was used as an input for discriminant analysis. In this paper, the mean, median, and standard deviation features were used. This experiment used fifteen leads consisting of twelve conventional leads and three posterior leads. The addition of the three leads had the advantage of determining the performance results obtained. By utilizing the mean feature, the experiment obtained the best accuracy of $97.73 \%$. This experiment attempted to compare the features of mean and standard deviation; mean and median; standard deviation and median; and mean, median, and standard deviation. The combined experiment showed that the best accuracy was $98.84 \%$, which was obtained using standard deviation and median features.
\end{abstract}

Intisari-Pada makalah ini dipaparkan deteksi myocardial infarction menggunakan fitur rata-rata statistik, yaitu rata-rata, median, dan simpangan baku. Klasifikasi yang digunakan adalah metode analisis diskriminan yang diimplementasikan menggunakan perangkat lunak MATLAB. Sinyal EKG yang didapatkan dari perangkat tersebut kemudian diproses, lalu dilakukan esktaksi fitur. Hasil dari proses ekstraksi tersebut dinormalisasi agar semua data pasien memiliki standar yang sama dalam besaran gelombang amplitudo. Setelah dilakukan normalisasi, data digunakan sebagai masukan analisis diskriminan. Makalah ini mencoba menggunakan fitur rata-rata, median, dan simpangan baku. Eksperimen ini menggunakan lima belas lead, yang terdiri atas dua belas lead konvensional dan tiga lead posterior. Penambahan tiga lead tersebut memberikan keuntungan dalam menentukan hasil kinerja. Akurasi terbaik yang didapatkan adalah $\mathbf{9 7 , 7 3 \%}$, yaitu dengan fitur rata-rata. Eksperimen ini mencoba membandingkan fitur rata-rata dan simpangan baku; rata-rata dan median; simpangan baku dan median; serta rata-rata, median, dan simpangan baku. Dari

${ }^{1}$ Prodi Fisika, Pasca Sarjana, Universitas Sebelas Maret, Jl. Ir. Sutami 36A Kentingan Jebres Surakarta 57126 (tlp: (0271) 632450; e-mail: dewicahyafitri@student.uns.ac.id)

${ }^{2}$ Prodi Fisika, FMIPA, Universitas Sebelas Maret, Jl. Ir. Sutami 36A Kentingan Jebres Surakarta 57126 (tlp: (0271)632450; e-mail: nuryani@mipa.uns.ac.id)

*Corresponding Author

${ }^{3}$ PTIK BPPT, Puspitek Serpong, Tangerang, 15314 (tlp: (021) 75791262; e-mail: anto.satriyo@bppt.go.id) eksperimen gabungan tersebut didapatkan akurasi yang terbaik adalah 98,84\%, yaitu pada fitur simpangan baku dan median.

Kata Kunci-Myocardial Infarction, Ekstraksi Fitur, Fitur Statistik, Analisis Diskriminan.

\section{Pendahuluan}

Myocardial Infarction (MI) atau disebut juga serangan jantung terjadi karena adanya penurunan myocardial perfusion sehingga menyebabkan nekrosis sel miokardia. Hal ini menunjukkan adanya obstruksi pada aliran darah akibat plak dalam arteri koroner. MI merupakan manifestasi dari penyakit jantung koroner yang lain, di antaranya termasuk unstable angina pectoris, MI dengan atau tanpa segmen elevasi ST [1].

American Heart Association (AHA) memperkirakan lebih dari 1 juta penduduk Amerika mengalami MI setiap tahunnya [2]. Sementara itu, organisasi kesehatan lainnya mencatat lebih dari tujuh juta orang meninggal akibat MI di seluruh dunia pada tahun 2002. Angka ini diperkirakan meningkat hingga sebelas juta orang pada tahun 2020 [3].

Kajian epidemiologis menunjukkan bahwa beberapa faktor yang dapat meningkatkan risiko seseorang mengalami MI di antaranya adalah usia, riwayat keluarga, obesitas, hiperlipidemia, merokok, diabetes melitus, jenis kelamin, ras, riwayat hipertensi, stres, dan kurangnya aktivitas fisik. Semakin banyak faktor risiko yang dimiliki oleh seseorang, semakin besar kemungkinan terjadinya MI [4].

Gejala klinis pada MI pada umumnya ditandai dengan adanya nyeri dada khas, yaitu nyeri dada tipikal. Nyeri dada dapat menjalar ke bagian lengan kiri, ke leher, rahang bawah, gigi, punggung atau interscapula, perut, dan dapat juga ke lengan kanan. Nyeri juga dapat dijumpai pada daerah epigastrium dan menstimulasi gangguan pada saluran percernaan, seperti mual dan muntah. Rasa tidak nyaman di dada dapat menyebabkan sulit bernafas, keringat dingin, cemas, dan lemas. Nyeri dada tidak selalu ditemukan pada pasien MI, terutama pada pasien yang lanjut usia atau menderita diabetes melitus [5].

Elektrokardiografi (EKG) merupakan gambaran grafis mengenai gambaran puncak aktivitas elektris dari serabut otot jantung, berupa kurva tegangan fungsi waktu yang terdiri atas berbagai puncak [6]. Gbr. 1 merupakan penggunaan EKG dilengkapi dengan pemasangan sadapan atau lead untuk memonitor adanya perubahan tegangan antara elektroda dalam tubuh. Sadapan tersebut memiliki dua belas lead konvensional, yang terdiri atas i, ii, iii, avr, avl, avf, v1, v2, v3, v4, v5, dan v6 [7]. 


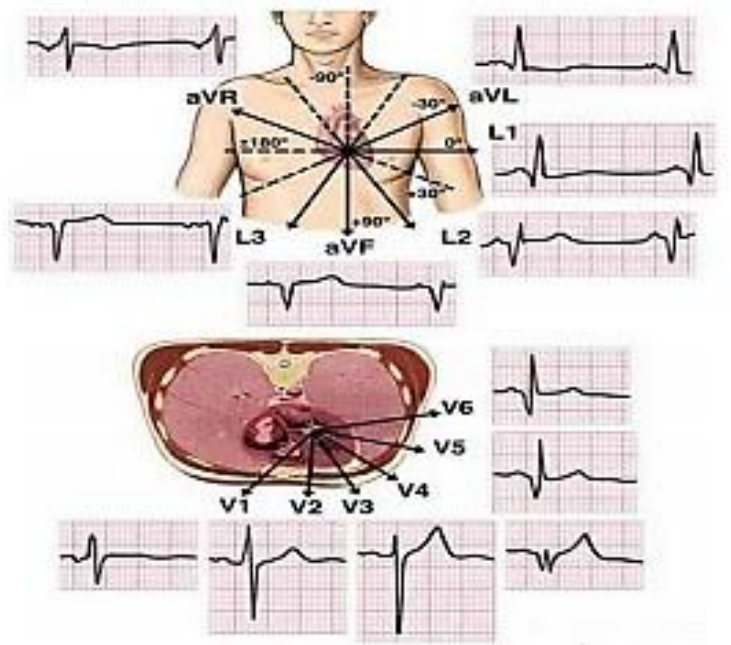

Gbr. 1 Pola gambar sinyal kardiografi.

EKG dengan dua belas lead memiliki keterbatasan dalam mengevaluasi keadaan pasien dan konsentrasi diagnosis MI. Keterbatasan ini merupakan hasil dari faktor yang sering ditemui oleh pasien iskemik, termasuk pola elektrokardiograf seperti blok cabang berkas kiri dan ritme pacu ventrikel. Hal ini seperti yang ditemui pada EKG yang sudah berkembang dan pada MI melibatkan area jantung, yang sulit digambarkan dengan EKG dua belas lead seperti pada Gbr. 1, misalnya dinding posterior ventrikel kiri dan ventrikel kanan [7]. Penambahan lead digunakan untuk menggambarkan keadaan dinding posterior ventrikel kiri dan ventrikel kanan. EKG standar yang digabungkan membentuk lima belas lead. Penggunaan tiga lead tambahan (vx, vy, dan vz) tidak hanya mengonfirmasi keadaan pasien MI, tetapi juga memberikan akurasi dari tingkat kerusakan miokardia yang sebenarnya [8].

MI yang terekam pada EKG mungkin terjadi pada segmen PR, kompleks QRS, dan segmen ST atau gelombang T. Manifestasi awal MI biasanya adalah perubahan gelombang $\mathrm{T}$ dan segmen ST. Peningkatan amplitudo gelombang $\mathrm{T}$ yang hiperakut dengan gelombang $\mathrm{T}$ simetris yang menonjol, setidaknya dua lead bersebelahan, merupakan tanda awal yang mungkin mendahului elevasi segmen ST. Perubahan akut atau perubahan dalam bentuk gelombang ST-T dan gelombang Q dapat terjadi sehingga kejadian tersebut memungkinkan untuk dilakukannya identifikasi arteri terkait infarction untuk memperkirakan jumlah miokardia yang berisiko serta prognosis dan menentukan strategi terapeutik [9].

Beberapa studi ini berhubungan dengan MI, yaitu terdapat hubungan antara invers gelombang $\mathrm{T}$ awal dan arteri terkait dengan MI. Posisi gelombang $\mathrm{T}$ yang terbalik secara bersamaan pada gelombang ST dapat menjadi penanda yang tepat untuk myocardial infarction [10]. Pada studi deteksi MI yang menggunakan gelombang EKG, peningkatkan akurasi dapat dilakukan menggunakan metode Multiple Instance Learning (MIL). Algoritme tersebut secara otomatis mendeteksi EKG dengan MI dan meningkatkan kualitas klasifikasi dari segi akurasi [11].

Suatu studi untuk deteksi MI berdasarkan dua belas lead menggunakan metode Convolutional Neural Network (CNN)

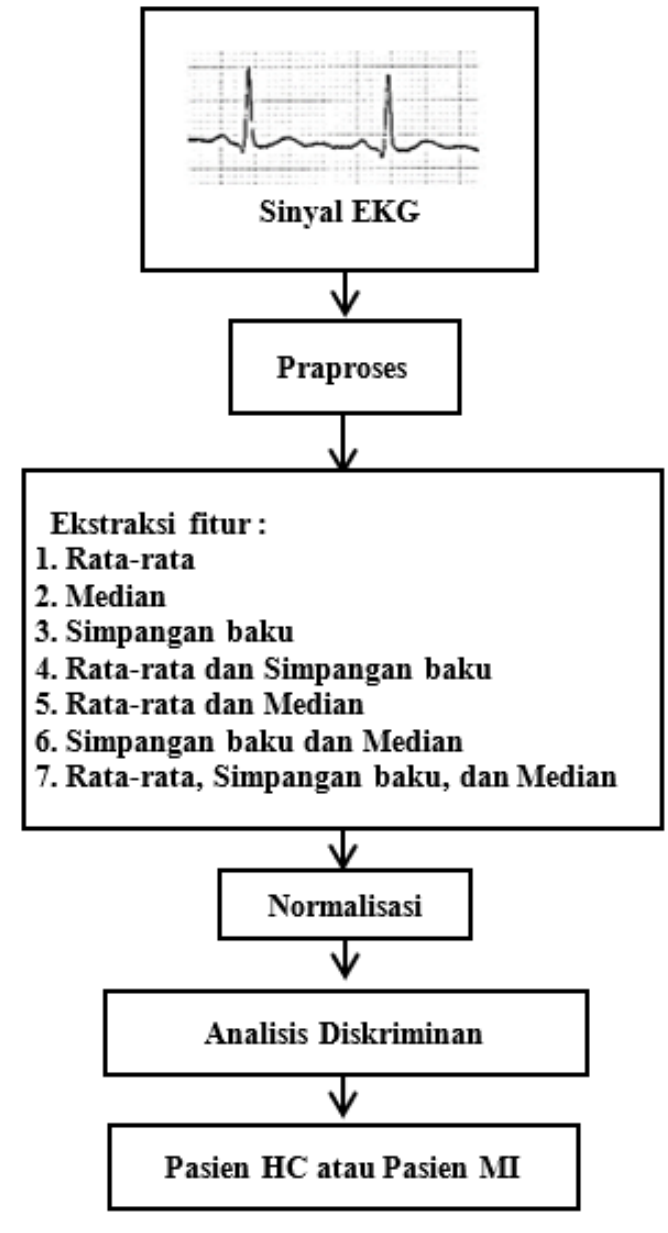

Gbr. 2 Rancangan sistem.

telah dilakukan. Eksperimen ini hanya menggunakan segmentasi detak jantung dengan segmen sinyal EKG selama 3 s serta menggunakan metode $\mathrm{CNN}$ dengan tiga belas lapisan untuk melatih sinyal tersebut, tidak menggunakan pemilihan ekstraksi fitur. Eksperimen ini dilakukan dengan dua set data EKG yang telah dihilangkan deraunya dan asli untuk menguatkan algoritme dalam sinyal. Dari eksperimen ini didapatkan hasil akurasi tertinggi tanpa mengghilangkan derau [12]. Metode CNN juga telah digunakan pada beberapa penelitian dan menunjukkan akurasi yang tinggi menggunakan metode lainnya dengan basis data yang sama dengan eksperimen yang menggabungkan empat lapisan [13].

Pada makalah ini dipaparkan sistem deteksi MI menggunakan fitur statistik dari segmen elevasi ST menggunakan ekstraksi fitur dengan metode analisis diskriminan. Klasifikasi yang digunakan adalah metode analisis diskriminan yang diimplementasikan menggunakan perangkat lunak MATLAB. Kontribusi makalah ini adalah penggunaan fitur statistik elevasi ST dengan analisis diskriminan untuk deteksi MI.

\section{Metodologi}

Data yang digunakan sebagai bahan eksperimen diambil dari Physikalisch-Technische Bundesanstalt (PTB) berupa EKG diagnostik dengan rancangan sistem seperti pada Gbr. 2. 


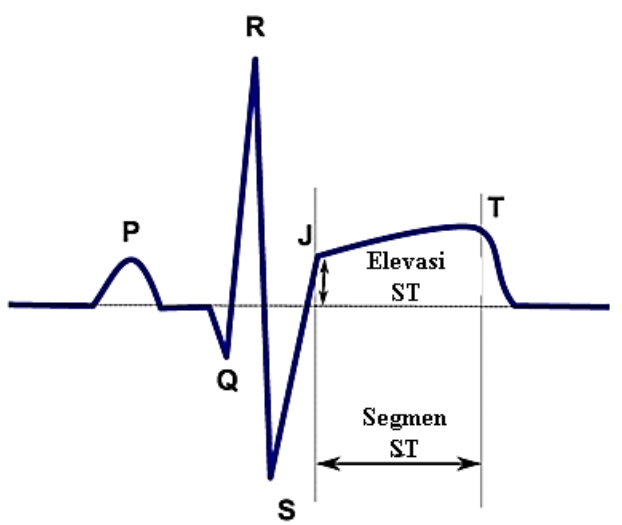

Gbr. 3 Segmen ST mengetahui posisi titik T dan J.

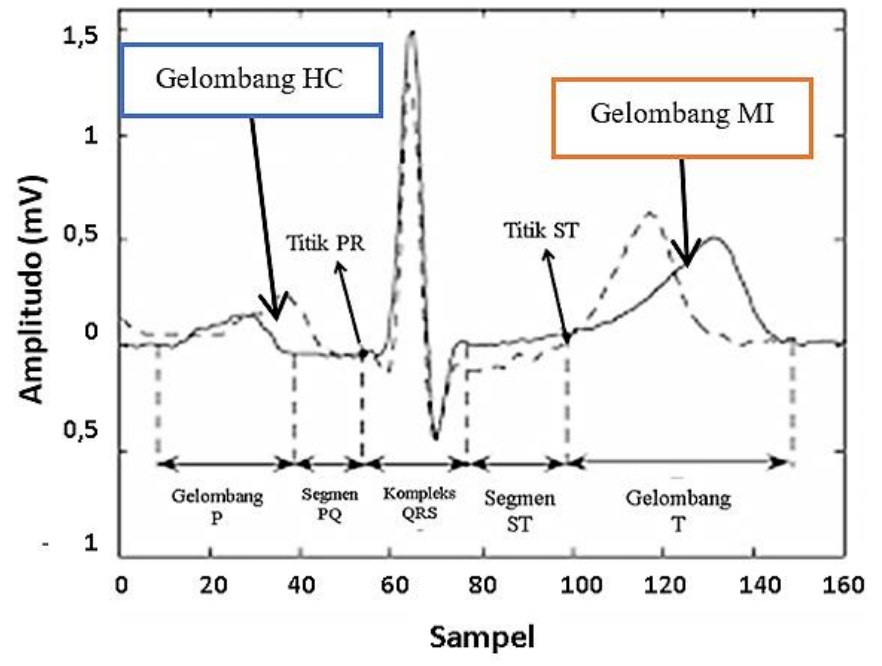

Gbr. 4 Perbedaan gelombang EKG pada MI dan HC.

Data pasien MI dan data normal (Health Control, HC) yang digunakan dalam eksperimen ini masing-masing sebanyak 148 pasien dan 52 pasien, masing-masing pasien mencakup lima belas lead. Sample rate setiap sinyal berkisar $1.000 \mathrm{~S} / \mathrm{s}$ dengan resolusi 16 bit dengan frekuensi cuplik hingga $10 \mathrm{kHz}$ [14].

Data mentah untuk studi ini berasal dari Physionet. Data pasien MI dan pasien normal tersebut selanjutnya akan diekstraksi agar diperoleh fitur yang dapat mencirikan gelombang MI yang berbeda dengan keadaan normal. Tahap ini dikenal dengan proses ekstraksi fitur.

Ekstraksi fitur diawali dengan penentuan titik $\mathrm{J}$ dan $\mathrm{T}$, seperti ditunjukkan pada Gbr. 3. Titik $\mathbf{J}$ dan $\mathrm{T}$ ini digunakan untuk menentukan panjang segmen ST, yaitu segmen waktu dari titik $\mathbf{J}$ sampai titik $\mathrm{T}$, seperti ditunjukkan pada Gbr. 4 [15]. Selanjutnya data segmen ini diolah lebih lanjut, yaitu berupa penentuan parameter statistiknya. Parameter statistik dari segmen ST ini digunakan sebagai masukan analisis diskriminan.

Penentuan ekstraksi fitur dilakukan dengan mengukur selisih dari titik $\mathbf{J}$ dan titik $\mathrm{T}$ pada Gbr. 1 dengan perhitungan ditunjukkan oleh (1). Posisi segmen ST adalah di antara akhir gelombang $\mathrm{S}$ dan awal gelombang $\mathrm{T}$, sedangkan titik $\mathrm{J}$ adalah posisi gelombang QRS berakhir dan segmen ST dimulai [15].

$$
S T_{\text {Segmen }}=\operatorname{mean}\left(U_{\text {point }}-T_{\text {point }}\right) .
$$

Setelah dilakukan ekstraksi fitur, proses selanjutnya adalah normalisasi, yang bertujuan agar semua data pasien memiliki standar yang sama dalam besaran gelombang amplitudo. Setelah dilakukan normalisasi, data digunakan sebagai masukan analisis diskriminan. Hasil dari normalisasi berada dalam rentang skala 0 sampai 1 , mengacu pada (2), dengan $S T_{\text {nor }}=S T$ yang telah dilakukan normalisasi dan $S T_{\text {fitur }}=S T$ dari setiap fitur [16].

$$
\left.S T_{\text {nor }}=\frac{S T_{\text {fitur }}-\min \left(S T_{\text {fitur }}\right)}{\left.\max _{\left(S T_{\text {fitur }}\right)}\right)^{-m i n}\left(S T_{\text {fitur }}\right)}\right) .
$$

Analisis dikriminan adalah analisis multivariate yang diterapkan untuk memodelkan hubungan antara satu variabel respons yang bersifat nonmetric, nominal, ordinal, dan bersifat kualitatif dengan satu atau lebih variabel bersifat kuantitatif. Model analisis diskriminan menunjukkan suatu kombinasi linear dari berbagai independen, yaitu $D$, yang merupakan skor diskriminan; $B$, yang merupakan koefisien diskriminan atau bobot; dan $X$, yang merupakan variabel independen [17].

$$
D=b_{0}+b_{1} X+b_{2} X_{2}+b_{3} K_{3}+\cdots+b_{k} X_{k}
$$

Data dari ekstraksi fitur dianalisis menggunakan analisis diskriminan untuk membedakan antara ritme $\mathrm{HC}$ dan ritme MI. Data yang didapatkan dibagi menjadi True Positive (TP), yaitu pasien yang memiliki penyakit MI; True Negative (TN), yang merupakan pasien memiliki penyakit $\mathrm{HC}$; False Positive (FP), yaitu pasien yang tidak memiliki penyakit tetapi hasil diagnosis menyatakan MI; dan False Negative (FN), yaitu pasien yang memiliki penyakit, tetapi hasil diagnosis menyatakan pasien HC. Setelah diklasifikasikan dengan metode tersebut, langkah selanjutnya adalah menentukan kinerja dengan menghitung akurasi. Akurasi merupakan kemampuan tes untuk mengidentifikasi hasil positif maupun negatif secara tepat. Akurasi dihitung dengan mengacu pada (4) [18].

$$
\operatorname{Akurasi}(\%)=\frac{T P+T N}{T P+T N+F P+F N} \times 100 \% .
$$

\section{HASIL DAN DISKUSI}

Sinyal EKG yang didapatkan lalu dikelompokkan ke dalam kelompok pasien MI dan pasien HC, seperti pada Gbr. 5 dan Gbr. 6. Karakteristik pasien MI ditandai dengan adanya perubahan pada gelombang segmen ST. Setelah pengelompokan tersebut, dilakukan penentuan titik perubahan dan peengukuran segmen ST, yaitu penentuan titik $\mathrm{T}$ dan titik J, seperti pada Gbr. 7 dan Gbr. 8 .

Setelah mencari titik $\mathrm{J}$ dan $\mathrm{T}$, selanjutnya dilakukan ekstraksi dengan lima fitur, yaitu nilai rata-rata, nilai tengah (median), nilai simpangan baku, nilai minimal, dan nilai maksimal. Eksperimen yang dilakukan juga menggabungkan fitur statistik tersebut, yaitu penggabungan antara nilai ratarata, median, dan simpangan baku. Langkah ini dilakukan per lead dengan menggabungkan semua kode pasien MI maupun $\mathrm{HC}$. 


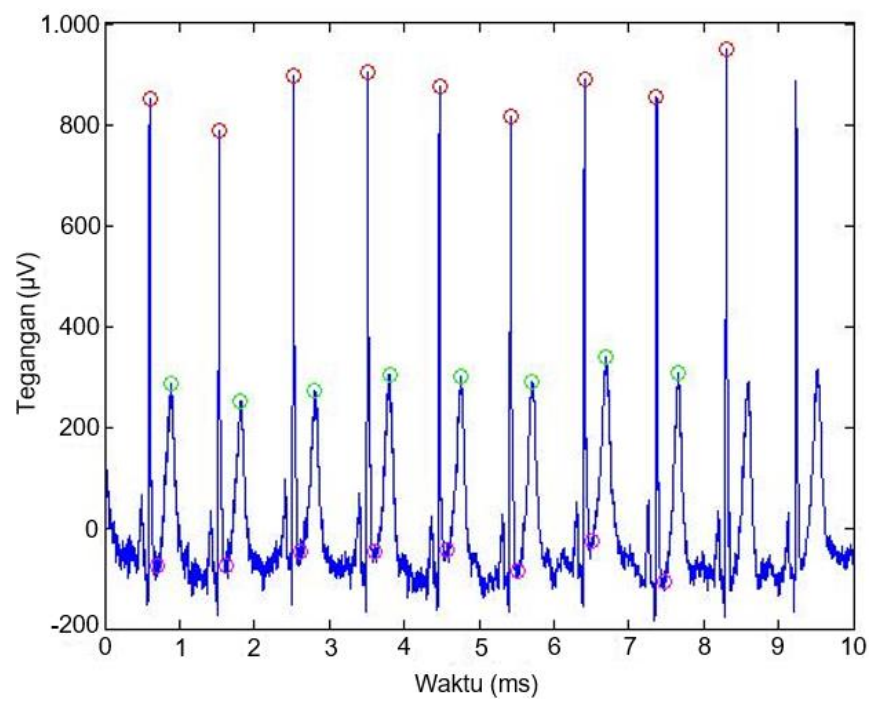

Gbr. 5 Gelombang EKG pada MI pasien kode s0037lrem lead 1.

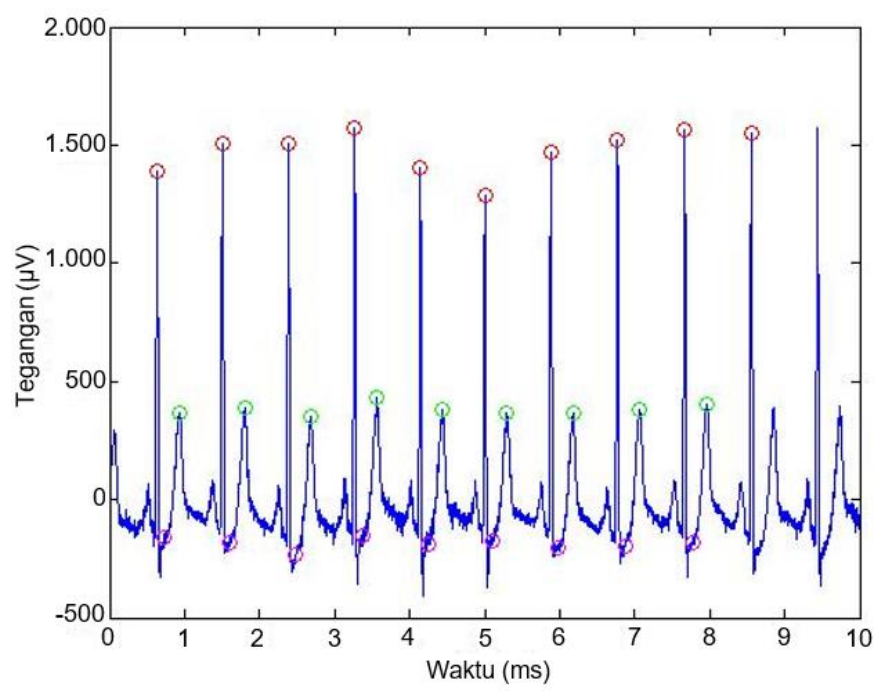

Gbr. 6 Gelombang EKG pada HC pasien kode s0304lrem lead 1.

Setelah dilakukan perhitungan fitur statistik segmen, ST langkah selanjutnya adalah normalisasi. Normalisasi dilakukan agar semua data pasien memiliki standar yang sama dalam besaran gelombang amplitudo. Hasil normalisasi berada dalam rentang skala 0 sampai dengan 1 , dengan nilai 0 merupakan pasien $\mathrm{HC}$ dan nilai 1 merupakan pasien MI.

Sebelum dilakukan normalisasi, semua data pasien, baik HI maupun HC, digabungkan menjadi satu. Setelah dilakukan normalisasi, dihasilkan lima belas lead, yang di dalamnya terdapat nilai lima ekstraksi fitur, yaitu rata-rata (F1); simpangan baku (F2); median (F3); rata-rata dan simpangan baku (F4); rata-rata dan median (F5); simpangan baku dan median (F6); serta rata-rata, median, dan simpangan baku (F7) dalam setiap pasien, seperti yang ditunjukkan pada Tabel I.

Hasil akurasi yang didapatkan per lead ditunjukkan pada Tabel I. Pada fitur sebelum penggabungan, diperoleh nilai tertinggi sebagai berikut. Pada lead 1 nilai tertinggi sebesar $87,36 \%$ dengan fitur rata-rata; pada lead 2 nilai tertinggi sebesar $83,72 \%$ dengan fitur median; pada lead 3 nilai yang

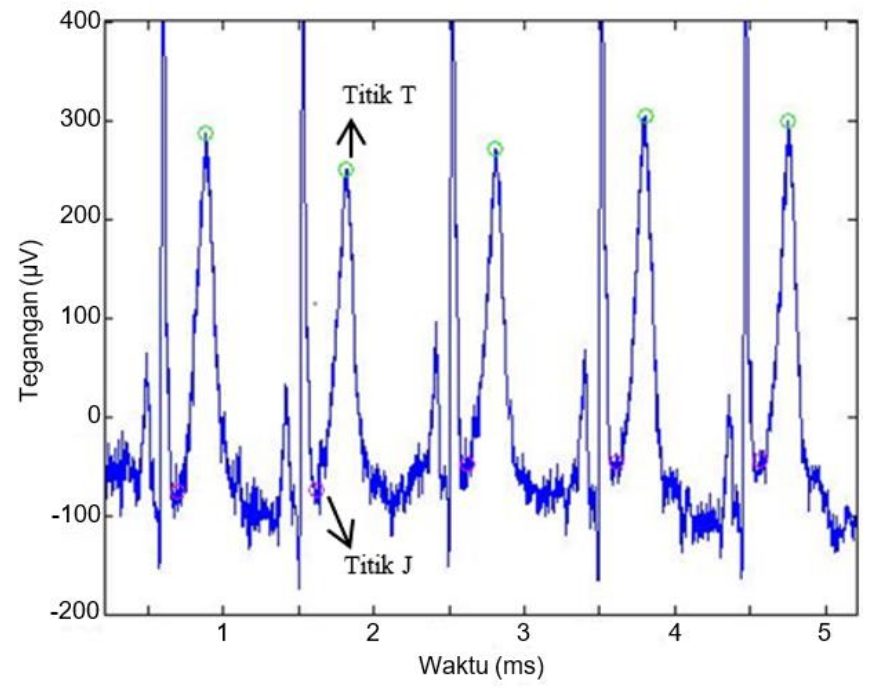

Gbr. 7 Posisi titik $\mathrm{J}$ dan titik $\mathrm{T}$ untuk menentukan segmen ST pasien MI dengan kode s0037lrem.

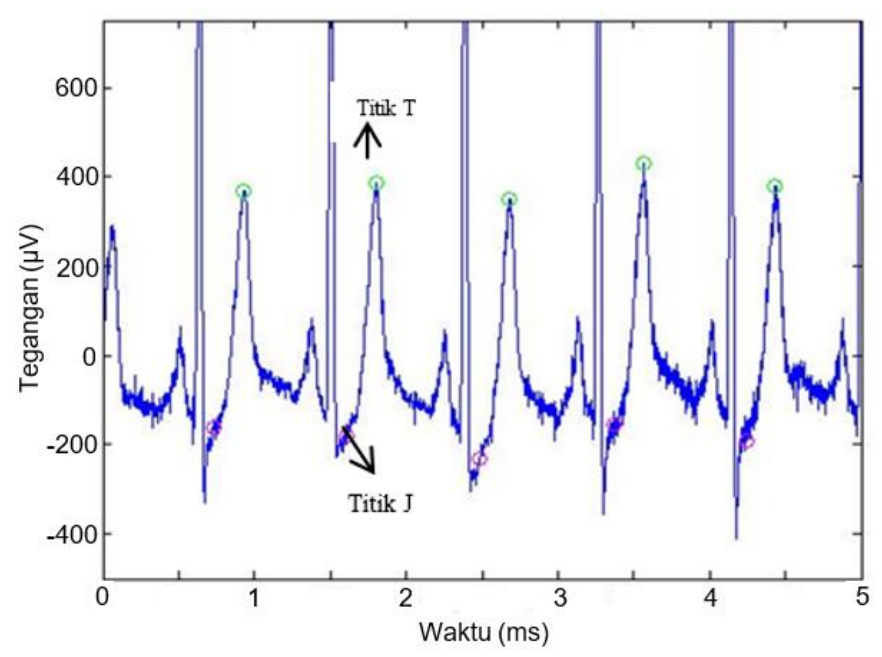

Gbr. 8 Posisi titik $\mathbf{J}$ dan titik $\mathrm{T}$ untuk menentukan segmen ST pasien HC kode s0304lrem.

tertinggi adalah simpangan baku, sebesar $81,61 \%$; pada lead 4 nilai tertinggi terdapat pada fitur median, sebesar $91,95 \%$; pada lead 5 nilai tertinggi adalah rata-rata, sebesar 95,40\%; pada lead 6 nilai tertinggi pada fitur simpangan baku, sebesar $81,61 \%$; pada lead 9 nilai tertinggi pada fitur rata-rata, sebesar $94,25 \%$; pada lead 10 nilai tertinggi pada fitur rata-rata, yaitu sebesar 97,67\%; pada lead 11 nilai tertinggi pada fitur ratarata, sebesar 95,35\%; pada lead 12 tertinggi pada fitur simpangan baku, sebesar 94,25\%; dan pada lead 13 nilai tertinggi pada fitur simpangan baku, yaitu sebesar 97,70\%.

Sementara itu, hasil akurasi tertinggi dengan fitur gabungan adalah sebagai berikut. Pada lead 3, nilai yang tertinggi terdapat pada penggabungan antara fitur simpangan baku dengan median, sebesar $81,61 \%$; pada lead 7 nilai tertinggi pada fitur penggabungan antara simpangan baku dengan median, sebesar $96,55 \%$; pada lead 8 nilai tertinggi pada fitur gabungan antara median dan rata-rata, sebesar 95,35\%; pada lead 9 nilai tertinggi pada pengabungan antara rata-rata dan median, sebesar 94,25\%; pada lead 11 nilai tertinggi pada 
TABEL I

AKurasi PENGUJian ANALisis Diskriminan SETIAP LEAD DAN FitUR YANG DigUnAKAN

\begin{tabular}{|c|c|c|c|c|c|c|c|}
\hline Lead & $\begin{array}{c}\text { F1 } \\
(\%)\end{array}$ & $\begin{array}{c}\text { F2 } \\
(\%)\end{array}$ & $\begin{array}{c}\text { F3 } \\
(\%) \\
\end{array}$ & $\begin{array}{c}\text { F4 } \\
(\%) \\
\end{array}$ & $\begin{array}{c}\text { F5 } \\
(\%) \\
\end{array}$ & $\begin{array}{c}\text { F6 } \\
(\%)\end{array}$ & $\begin{array}{c}\text { F7 } \\
(\%)\end{array}$ \\
\hline Lead 1 & 87,36 & 80,46 & 78,56 & 86,27 & 83,91 & 77,91 & 80,51 \\
\hline Lead 2 & 56,32 & 81,40 & 83,72 & 73,53 & 52,33 & 80,46 & 64,10 \\
\hline Lead 3 & 73,56 & 81,61 & 55,81 & 68,63 & 75,86 & 81,61 & 65,25 \\
\hline Lead 4 & 70,93 & 83,72 & 91,95 & 87,38 & 66,67 & 89,05 & 71,19 \\
\hline Lead 5 & 95,40 & 81,61 & 80,23 & 86,41 & 90,80 & 77,91 & 86,44 \\
\hline Lead 6 & 73,26 & 81,61 & 80,23 & 62,75 & 68,97 & 80,68 & 65,25 \\
\hline Lead 7 & 93,10 & 96,55 & 95,40 & 94,17 & 95,45 & 96,55 & 93,22 \\
\hline Lead 8 & 94,25 & 94,25 & 90,80 & 89,22 & 95,35 & 93,10 & 89,83 \\
\hline Lead 9 & 94,25 & 90,80 & 93.02 & 91,26 & 94,25 & 90,70 & 88,24 \\
\hline Lead 10 & 97,67 & 93,10 & 95,40 & 92,23 & 93,10 & 94,25 & 90,68 \\
\hline Lead 11 & 95,35 & 93,02 & 89,66 & 90,29 & 95,35 & 91,95 & 88,98 \\
\hline Lead 12 & 93,02 & 94,25 & 94,19 & 90,20 & 93,10 & 94,25 & 87,29 \\
\hline Lead 13 & 97,73 & 97,70 & 93,10 & 93,14 & 94,19 & 96,51 & 91,25 \\
\hline Lead 14 & 78,16 & 87,36 & 84,88 & 98,06 & 77,01 & 82,76 & 65,25 \\
\hline Lead 15 & 96,55 & 96,59 & 96,51 & 81,55 & 95,40 & 98,84 & 94,07 \\
\hline
\end{tabular}

penggabungan antara rata-rata dan median, sebesar 95,35\%; pada lead 12 nilai tertinggi pada penggabungan simpangan baku dan median, sebesar 94,25\%\%; pada lead 14 nilai tertinggi terdapat pada fitur gabungan antara rata-rata dan simpangan baku, sebesar 98,06\%, dan pada lead 15 nilai tertinggi akurasi diperoleh pada fitur gabungan antara simpangan baku dan median, yaitu sebesar $98,84 \%$.

Nilai akurasi terendah yang dihasilkan eksperimen ini adalah sebagai berikut. Pada lead 1 nilai terendah diperoleh pada fitur gabungan antara simpangan baku dan median, sebesar 98,06\%; nilai terendah pada lead 2 diperoleh fitur gabungan rata-rata dan median, sebesar 52,33\%; pada lead 3 nilai terendah pada fitur median, sebesar $55,81 \%$; pada lead 4 nilai terendah pada fitur gabungan antara rata-rata dan median, sebesar $66,67 \%$; nilai terrendah pada lead 5 pada fitur gabungan antara simpangan baku dan median, sebesar 77,91\%; dan pada lead 6 nilai terendah diperoleh pada fitur gabungan antara rata-rata dan median, yaitu sebesar 68,97\%.

\section{KESIMPULAN}

Telah dilakukan studi tentang identifikasi MI dari sinyal EKG menggunakan metode analisis diskriminan dengan fitur statistik elevasi segmen ST. Studi ini menggunakan lima belas lead (dua belas lead konvensional dan tiga lead posterior). Pada penggunaan fitur statistik tunggal, akurasi terbaik yang diperoleh adalah 97,73\%, yaitu pada lead 13 menggunakan rata-rata. Untuk penggunaan kombinasi fitur statistik, akurasi terbaik yang diperoleh adalah 98,06\%, yaitu pada lead 14 dengan fitur statistik rata-rata dan simpangan baku.

\section{REFERENSI}

[1] S. Boateng dan T. Sanborn, "Acute Myocardial Infarction," Dis Mon, Vol. 59, No. 3, hal. 83-96, 2013.

[2] E.M. Antman, D.T. Anbe, P.W. Armstrong, E.R. Bates, L.A. Green, M Hand, dkk., "ACC/AHA Guidelines for the Management of Patient with
ST Elevation Myocardial Infarction," Circulation, Vol. 110, No. 5, hal. 588-636, 2004.

[3] (2011) Kementerian Kesehatan Republik Indonesia website, [Online], http://www.depkes.go.id, tanggal akses 19-Nov-2020.

[4] C. Smeltzer, B.G. Bare, Brunner, dan Suddarth, Textbook of Medical Surgical Nursing, 11th ed., Philadelphia, USA: Wolters Kluwer, 2010.

[5] D.D. Ignativicius dan M.L. Workman, Medical Surgical Nursing: Critical Thinking for Collaborative Care, 4th ed., St. Louis, USA: Elsevier Saunders, 2006.

[6] A. Heru, "Desain Alat Deteksi Dini dan Mandiri Aritmia," J. Teknol. Manaj. Informatika, Vol. 6, No. 3, hal. 494-502, 2008.

[7] R.K. Tripathy, A. Bhattacharyya, dan R.B. Pachori, "Localization of Myocardial Infarction from Multi-Lead ECG Signals Using Multiscale Analysis and Convolutional Neural Network," IEEE Trans. Biomed. Eng., Vol. 19, No. 23, hal. 11437-11448, 2019.

[8] W.J. Brady, V. Hwang, R. Sullivan, N. Chang, C. Beagle, C.T. Carter, M.L. Martin, dan T.P. Aufderheide, "A Comparison of 12- and 15-Lead ECGs in ED Chest Pain Patients: Impact on Diagnosis, Therapy, and Disposition," Am. J. Emerg. Med., Vol. 18, No. 3, hal. 239-243, 2000.

[9] H. Munirwan dan R. Pebriana, "Evolusi EKG pada STEMI dengan Gelombang Q Patologis: Haruskah Menunda Terapi?," J. Ked. N. Med., Vol. 3, No. 1, hal. 21-29, 2020.

[10] A. Ranjbar, B. Sohrabi, S.R.S. Ebrahimi, S. Ghaffari, B. Kazemi, N. Aslanabadi, B. Seyvani, dan R. Hajizadeh, "The Association between T Wave Inversion in Leads with ST-Elevation and Patency of the Infarctrelated Artery," BMC Cardiovascular Disorders, Vol. 21, No. 1, hal. 16, 2021.

[11] L. Sun dan Y. Lu, "ECG Analysis Using Multiple Instance Learning for Myocardial Infarction Detection," IEEE Trans. Biomed. Eng., Vol. 59, No. 12, hal. 3348-3356, 2012.

[12] N. Liu, L. Wang, Q. Chang, Y. Xing, dan X. Zhou, "A Simple and Effective Method for Detecting Myocardial Infarction Based on Deep Convolutional Neural Network," J. Med. Imaging Health Inf., Vol. 8, No. 7, hal. 1508-1512, 2018.

[13] X. Lun, Z. Yu, T. Chen, F. Wang, dan Y. Hou, "A Simplified CNN Classification Method for MI-EEG via the Electrode Pairs Signals," Front. Hum. Neurosci., Vol. 14, hal. 1-14, 2020.

[14] R. Bousseljot, D. Kreiseler, dan A. Schnabel, "Nutzung der EKGSignaldatenbank CARDIODAT der PTB über das Internet," Biomedizinische Technik, Vol. 40, No. s1, hal. 317-318, 1998. 
[15] D.H. Lee, J.W. Park, J. Choi, A. Rabbi, dan R.F. Rezai, "Automatic Detection of Electrocardiogram ST Segment: application in Ischemic Disease Diagnosis," Int. J. Adv. Comput. Sci. Appl., Vol. 4, no. 2, hal 150-155, 2014.

[16] B. Sartono, F.M. Affendi, U.D. Syafitri, I..M. Sumertajaya, dan Y. Anggraeni, Analisis Peubah Ganda, Bogor, Indonesia: IPB Press, 2003.
[17] R.L. Tatham, J.F. Hair, R.E. Anderson, dan W.C. Black, Multivariate Data Analysis, Hoboken, USA: Prentice Hall, 1998.

[18] W. Zhu, N. Zeng, dan N. Wang, "Sensitivity, Specificity, Accuracy, Associated Confidence Interval and ROC Analysis with Practical SAS Implementation," NESUG Proceeding: Health Care and Life Sciences, 2010, hal. 1-9. 